\title{
The importance of the „0"state in the context of dynamic influences
}

\author{
Alicja Kowalska-Koczwara ${ }^{* 1}$, Krzysztof Stypula ${ }^{1}$, Jozef Melcer ${ }^{2}$ \\ ${ }^{1}$ Cracow University of Technology, Faculty of Civil Engineering, Krakow, Poland \\ ${ }^{2}$ Faculty of Civil Engineering, University of Zilina, Slovak Republic
}

\begin{abstract}
Nowadays, in the increasingly expanding of dynamical influences in the more and more urbanized cities and increased awareness of the owners of the buildings vibrations could be a problem. This paper considers the problem of an inventory of buildings damages as collateral for the investor as well as for owners of buildings located in the zone of dynamical influences. The "0" state inventory could be very helpful base. In this article good practice guidelines during such inventory are clearly described.
\end{abstract}

Keywords: vibrations, dynamic influences, inventory of buildings damage, inventory card of a building.

\section{Introduction}

Fast expansion of building development in the city centers in Poland and the increase of residents' awareness about the environmental influences could be a problem for building and mining companies which are operating in the city zone. Vibrations together with noise are one of the sources of pollution often neglected during designing and building process. Vibrations are transmitted to the buildings by the soil and have the influence on the building structure and on residents of the building. Vibrations that could be found in urban space mostly coming from traffic [1], building process [2] but could be also induced by mining shock $[3,4]$. People are more sensitive to vibrations than the structure, which may result in negative comments. One of the solution for negative comments and protection for building and mining companies could be an inventory made before appearance of dynamic excitation. That kind of inventory is called " 0 " state inventory. The aim of this article is to give some guidelines for investors how to make good inventory. During the inventory some aspects like: how to determine proper zone of dynamical influences in which are buildings exposed to vibrations, who should make inventory of building damages and what information should be taken into account. In this article some important information for experts making an inventory could be found.

\footnotetext{
* Corresponding adres: akowalska@pk.edu.pl
} 


\section{An inventory according to the Polish Law}

An inventory of the building structure according to the Building Law is the description of the existing state. An inventory should be made in the case of all major interference in the building structure, such as: rebuild of building object, the changes in building partitions, etc. In that case the owners are interested in making such an inventory.

Making an inventory is obligatory (acc. to Building Law) in the cases of structural repairs, rebuilding of some parts of the building or superstructure and when roof structure will be changed or the dimensions of windows and doors will be changed. An inventory is one of documents in the technical documentation.

Inventory of the building will also be useful in other cases, for example in the assessment of the technical condition of the building, planned purchase or sale of real estate, new installations at home (gas, electricity, water, heating) or planned separation of new residential or commercial premises in the facility.

In the cases described above, one can refer to a construction inventory. However, another type of inventory is required to assess the technical condition of the building - damage inventory. Environmental protection law [5] imposes on the investor the obligation to reduce pollutant emissions (including vibrations - Article 3, point 4 of the Act [5]). The norm [6] specifies how to assess the impact of vibrations on buildings. In none of these legal acts (also in [7]), which is understandable, the need to carry out the inventory of damage to a construction object was not specified. The Construction Law does not impose an obligation to draw up such an inventory, but imposes on the manager or owner the obligation to keep the building in proper technical condition in order to ensure safe use of the building (Article 61 of the Act [7]). The Act [7] also imposes an to make a technical inspection of the building once a year, but does not specify how this inspection should look like and by whom it should be performed. The exceptions are installations which inspection should be carried out by persons having appropriate qualifications. However, this obligation does not apply to owners of single-family residential buildings (Article 62, point 2 of the Act [7]). In turn, an inventory of damage to structures may, according to the Act [7], be ordered by the building inspector if doubts arise as to the technical condition of the building.

\section{Inventory stages}

The investor, after making a decision about the inventory of damage to structures exposed to vibrations, must decide on the range of the dynamic influence zone. The zone of dynamic influences is the area in which it is required taking into account the vibrations transmitted through the ground. The range of this zone should be determined as a result of dynamic measurements, because it is affected by soil and water conditions, which are not always fully recognized. The approximate values of the ranges of the dynamic impact zone depending on the source of vibrations are summarized in Table 1 (acc. [8]). 
Table 1. Range of the dynamic influences depending on the source of vibrations

\begin{tabular}{|c|c|c|}
\hline \multirow{2}{*}{ Source of vibration } & \multicolumn{2}{|c|}{ Range of the influence zone } \\
\hline & $\begin{array}{l}\text { Influence } \\
\text { on structure }\end{array}$ & $\begin{array}{l}\text { Influence } \\
\text { on people }\end{array}$ \\
\hline $\begin{array}{l}\text { Railway line } \\
\text { With passenger traffic } \\
\text { With freight and mixed traffic }\end{array}$ & $\begin{array}{l}25 \mathrm{~m}^{*} \\
35 \mathrm{~m} \\
45 \mathrm{~m}\end{array}$ & $\begin{array}{l}65 \mathrm{~m} \\
80 \mathrm{~m}\end{array}$ \\
\hline Tram line, wheel road & $15 \mathrm{~m}$ & $25 \mathrm{~m}$ \\
\hline Line of a shallow underground & $15-25 \mathrm{~m}$ & $40 \mathrm{~m}$ \\
\hline Driving of foundation piles & $40-60 \mathrm{~m}$ & $--* *$ \\
\hline $\begin{array}{l}\text { Soil compaction by } \\
\text { vibratory roller }\end{array}$ & $20-60 \mathrm{~m}$ & $--* *$ \\
\hline $\begin{array}{l}\text { Driving of sheet piling with } \\
\text { vibratory hammer }\end{array}$ & $30 \mathrm{~m}$ & $--* *$ \\
\hline $\begin{array}{l}\text { Driving of sheet piling with } \\
\text { shock hammer }\end{array}$ & $20 \mathrm{~m}$ & $--* *$ \\
\hline \multicolumn{3}{|c|}{$\begin{array}{l}* \text { in Polish standard [5] for newly designed buildings } \\
* * \text { the impact on people is neglected in the case of construction works }\end{array}$} \\
\hline
\end{tabular}

The ranges of the dynamic impact zone given in the table above refer to medium ground conditions and to undamaged buildings with a typical structure. Remembering about these conditions, the investor may increase the scope of the inventory. Such a situation took place while preparing the expertise [9]. The investor decided to include a damage inventory of buildings located in the distance of $60 \mathrm{~m}$ from the edge of the modernized road.

The most favourable situation is when the damage inventory covers all structures located in the zone of dynamic influences, and not only selected due to visible bad technical condition. Complaints are often made by users of buildings in the good technical condition, and not by the owners of neglected buildings.

The second stage of preparation for the inventory of damage to buildings located in the dynamic impact zone is to obtain consent from the owners of the construction works to carry out the inventory. Here, one can often encounter a problem, because the owners for whom the inventory should be also in the interest, do not necessarily want to make the object available for inventory purposes. An investor commissioning a damage inventory should therefore choose experts for this purpose with experience in this area. 
After obtaining the consent of the user of the structure, the damage inventory starts. The result of the damage inventory should be the card of the object being inventoried. The card should contain the following information:

a) general description of the building, in particular: address, surname of the owner, purpose of the building (residential, office etc.), type of building (detached, terraced house), situational plan - mainly location relative to the new investment (see Fig. 1), year of construction, dimensions of the building in a plan, number of storeys (with the specification whether there is a usable attic and / or a basement),

b) description of the structure of the building, which should include information about: type of construction (wall, frame, reinforced concrete etc.), foundations, walls, ceilings, roof structure, stairs construction,

c) description of the condition of the building, where the description of damage should be carried out from the general to the detail,

d) detailed description of the damages with width and depth of scratches if it is possible. e)

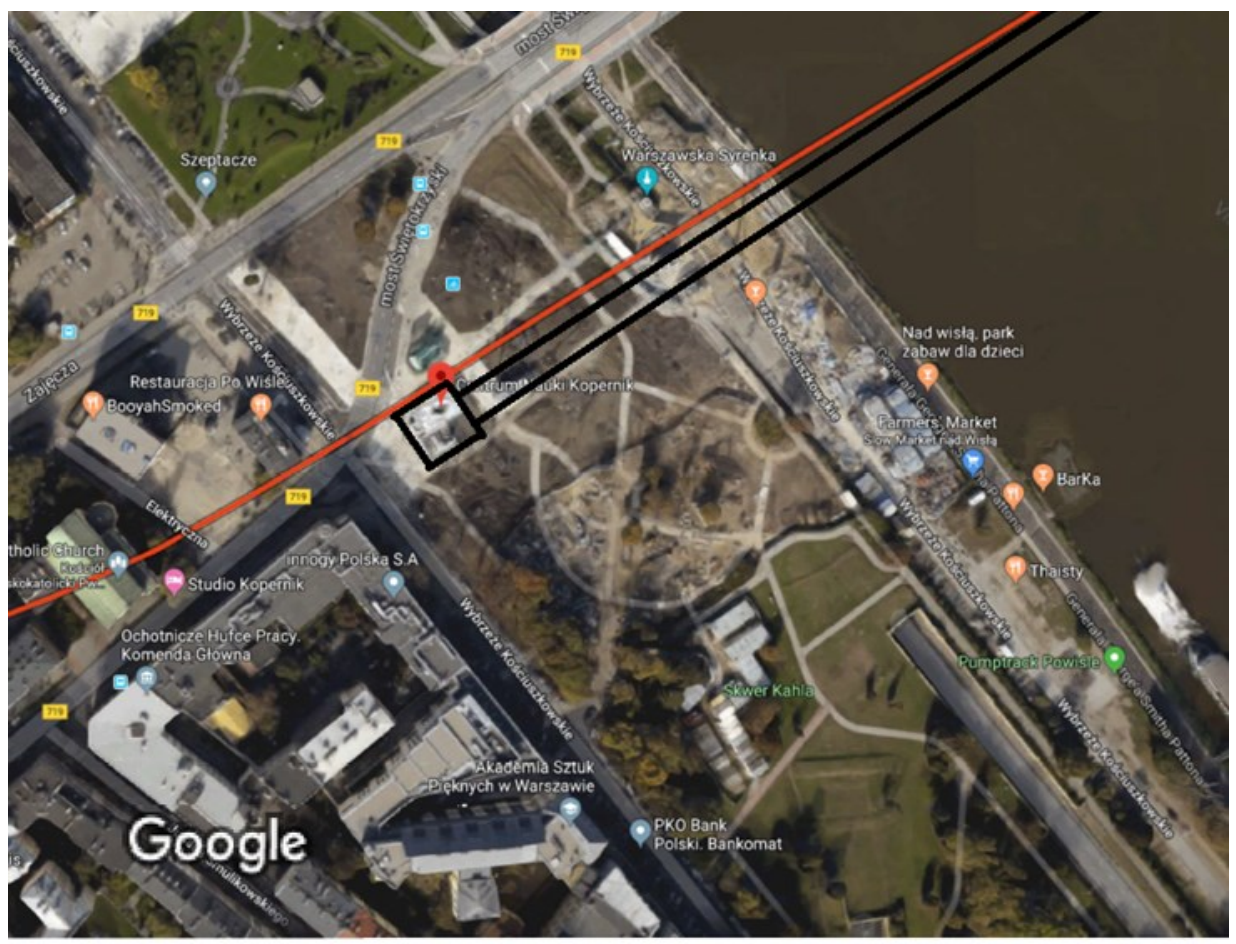

Imagery @2019 Google, Map data @2019 Google $20 \mathrm{~m}$

Fig. 1. Situation plan example (source: google.maps.pl)

When the inventory of damage to the building façade is finished, it is possible to start description of the damages inside the building. The mentioned above principle should be applied - from the general to the specific (see Fig. 2, 3, 4 and 5).

The adoption of the principle from the general to the detail makes it easier to locate inventoried damage and facilitates the description of damage after a local inspection. The description of the damage should contain information about the type of damage (crack, scratch, burn, etc.) if it is possible. The description should include information on the location of the damage, e.g. on the eastern wall of the kitchen in the central part, a vertical crack along 
the whole height. If possible, it should also be stated if there are surface damage or crosscracks, i.e. passing "through" the wall.

The description of the state of the building completes the inventory of damage to the building. However, one should remember about the signature of the owner of the object, which is a confirmation of the findings of the persons carrying out the inventory.
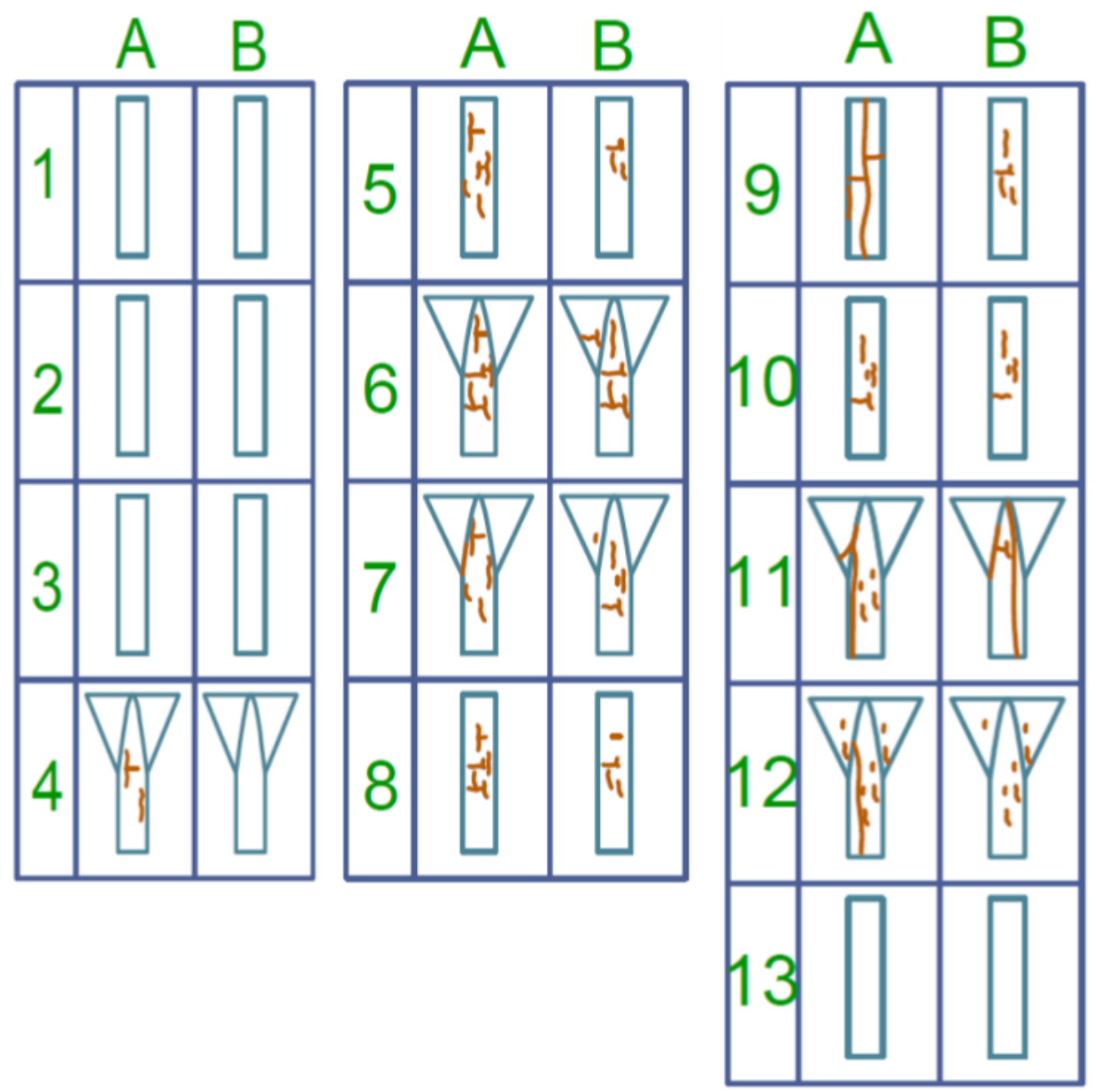

Fig. 2 View of the scratches on construction pillars 

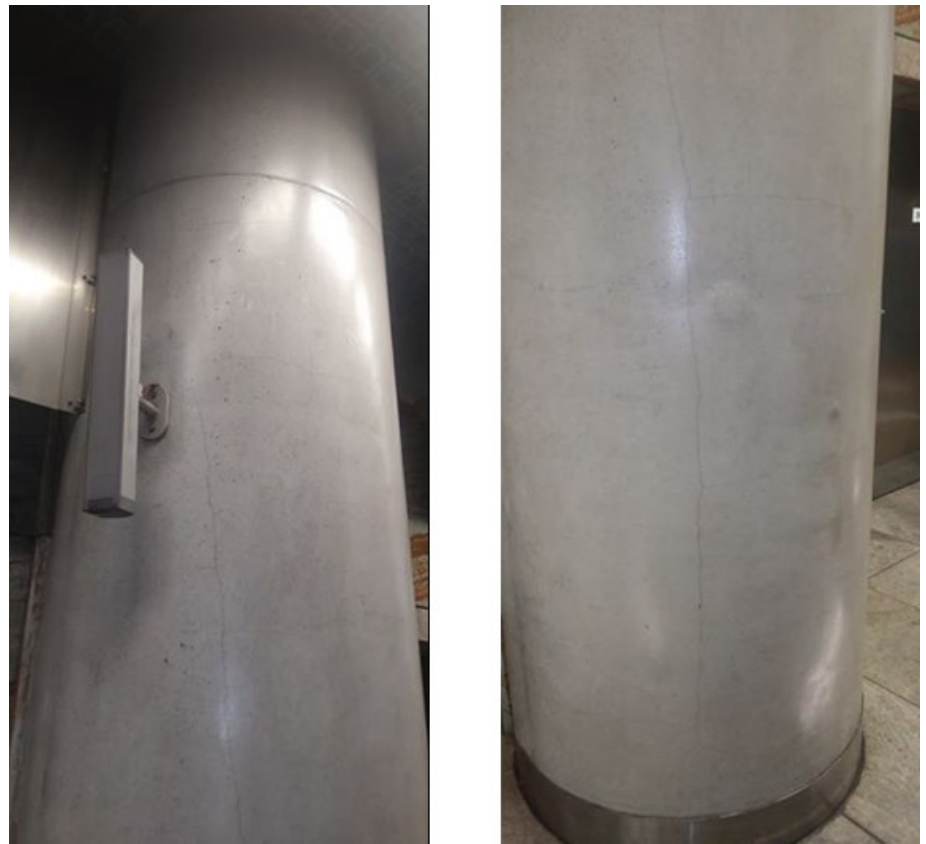

Fig. 3 View of scratches on a single pillar
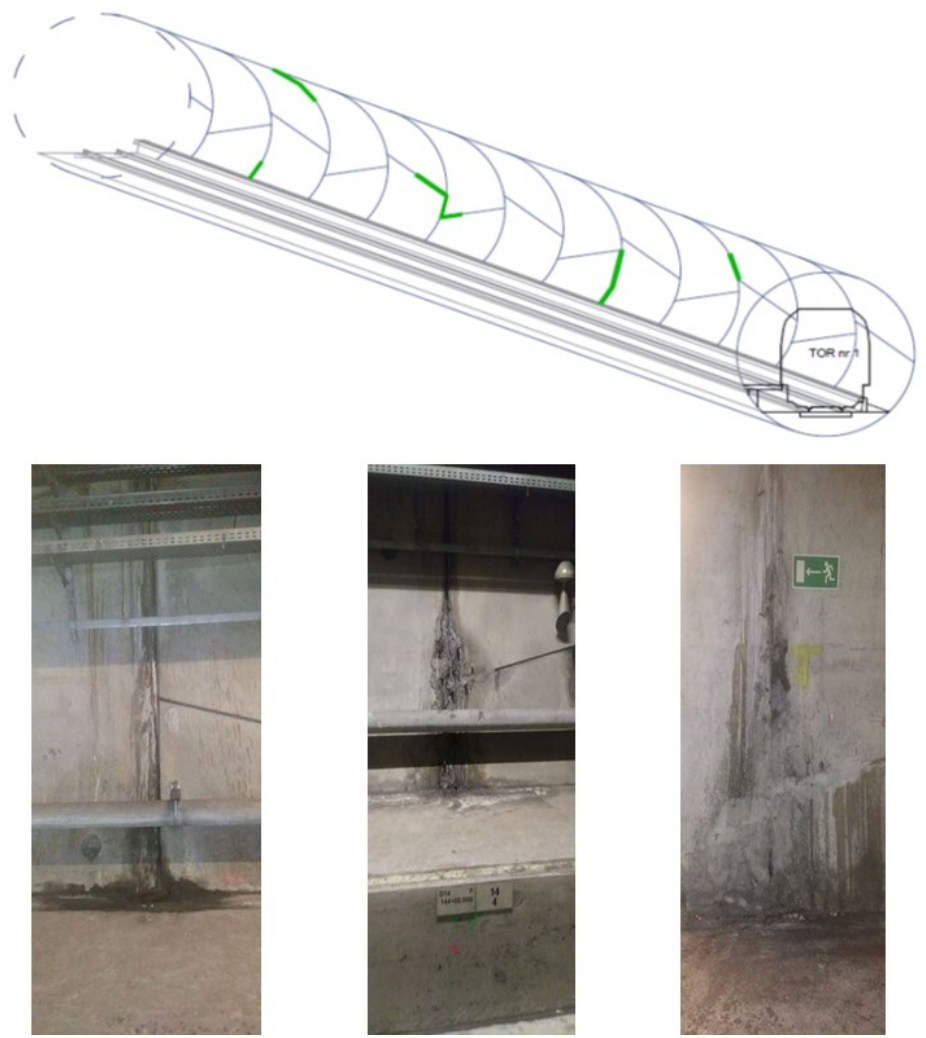

Fig. 4 View of scratches in the metro tunnel and photos of damages of single walls in the tunnel 

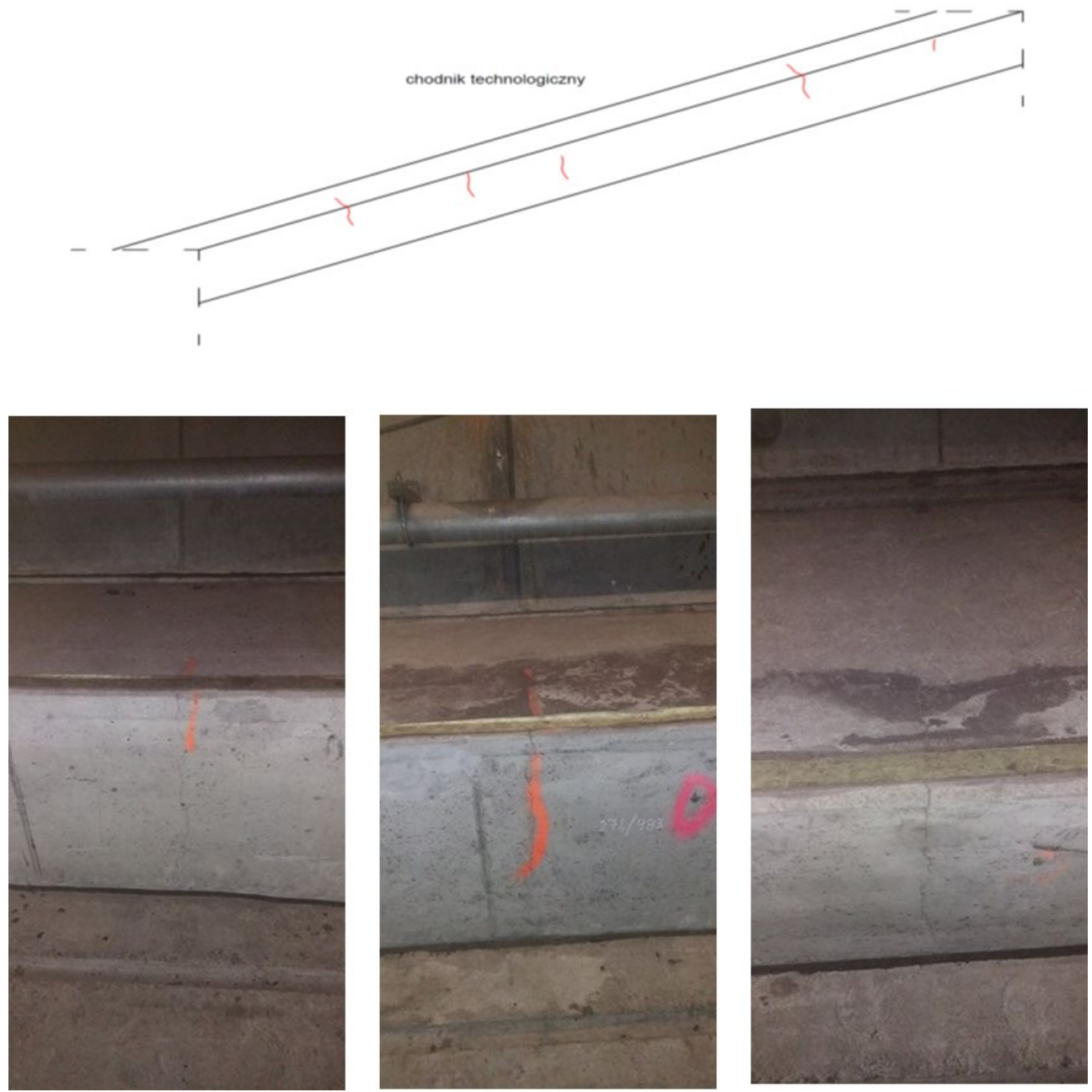

Fig. 5 View of scratches on the technical sidewalk and photos of damages on the single flagstone

\section{Conclusions}

Inventory of damage to buildings, although not required by law, may provide safety margin for the investor who plans construction or modernization, but also for the owner of the facility located near the planned investment. Inventory of damages should include buildings located in the so-called zones of dynamic influence. The investor should select for such inventory a person with experience and knowledge that will allow reliable preparation of the inventory card of the construction object. The description of the damage to the building in the card should be preceded by the description of the structure of the building, which already imposes the choice of people who have knowledge about construction. A properly prepared building object card is a document that can be the basis for settling disputes. It is worth to remember that people are much more sensitive than structures [9], and that people complain, not structures. 


\section{References}

1. V. Valašková, D. Papán, Z. Papánová, JME, v. 6, iss. 4, (2018)

2. G.A. Athanasopoulos, P.C. Pelekis, SOIL DYN EARTHQ ENG 19 (2000) 371 387

3. T. Tatara, F. Pachla, Ed., no. 40 in Geotechnical, Geological and Earthquake Engineering, Springer, pp. 275-287

4. E Pilecka, D. Szwarkowski: E3S Web of Conferences, Vol. 36, No. 02007 (2018)

5. Environmental Protection Law of April 27, 2001 (Journal of Laws of 2001, No. 62, item 627) (in Polish)

6. PN-B-02170:2016-12- Evaluation of harmfulness of vibrations transmitted by the ground to buildings (in Polish)

7. The Act of 7 July 1994 "Construction Law" (Journal of Laws of 1994 No. 89 item 414)

8. Stypuła K.: New investments and environmental protection against vibrations. Izolacje 10/2008. (in Polish)

9. An expertise "Inventory of the " 0 " state of the Metro structure (CNK station) and vibration monitoring of this building during works under the "Development of the Left Bank Vistula Boulevard stage 1 episode 1.3 ». Cracow, 2018, (in Polish) 